\title{
Social Support Among Heart Disease Patients: A Critical Review of Literature
}

\author{
Phillip Nhlanhla \\ University of South Africa, College of Human Sciences, Pretoria, SOUTH AFRICA
}

Received 15 May 2019 • Revised 20 August 2019 • Accepted 31 October 2019

\begin{abstract}
The aim of this paper was to critically review literature regarding the social support among heart disease patients. Social support has been prospectively associated with prognosis among heart disease patients. Psychosocial factors such as depression and low social support are established risk factors for poor prognosis in patients with heart disease. Patients living with heart disease who receive proper social support have a better prognosis than those who do not have this support. This is a qualitative meta synthesis study. Thus, literature on social support among heart disease patients were searched and reviewed. Information about the available social support, beneficial supportive actions, social support factors contributing to heart disease, and social support challenges faced by heart disease patients were identified and discussed. The paper concludes that information regarding social support available to heart disease patients, supportive actions beneficial to heart disease patients, social support factors contributing to heart disease and social support challenges faced by heart disease patients is paramount for the development of a clinical assessment tool and support model for heart disease patients; and recommends that identified information should be used to develop a clinical assessment tool to obtain baseline social support information from every heart disease patient, to inform effective social support interventions.
\end{abstract}

Keywords: social support, heart disease, available support, challenges, support factors.

\section{Introduction}

Coronary heart disease is the major cause of morbidity and mortality in the world. An estimated 17.5 million people across the globe die of heart-related diseases annually (WHO, 2014). The World Health Organization has predicted that heart-related disease is likely to be the leading cause of mortality by 2020. Russia alone has earlier recorded about 5.8 million deaths because of tobacco smoking between 1980 and 2000. It is estimated that 70 million people in Africa live with heart-related diseases (WHO, 2014) and every day about $9.2 \%$ of these patients die of heartrelated diseases. About 210 people are dying of heart disease every day in South Africa (Health 24, 2016). Psychosocial factors such as depression and low social support are established risk factors for poor prognosis in patients with heart disease.

According to Jacobs (2016), after a heart diagnose or a heart surgery, depression incidence goes up. Twenty per cent of heart patients will have at least mild depression according to WHO (2012). One possible reason is that people are suddenly faced with their own mortality, which is very depressing. Depression itself is a risk factor for cardiac mortality after someone has

(C) Authors. Terms and conditions of Creative Commons Attribution 4.0 International (CC BY 4.0) apply. Correspondence: Phillip Nhlanhla, Lecturer, College of Human Sciences, University of South Africa, Pretoria, SOUTH AFRICA. E-mail: nhlanpp@unisa.ac.za. 
had a cardiac event. According to Jacobs (2016), people who are well supported are less likely to become depressed. People who have social support are much more likely to be adherent to their treatment regimen, to go to cardiac rehabilitation, take their medication and eat well.

In September 2014 a study of 3,432 patients aged 55 and younger, published in the Journal of the American Heart Association, found that patients who had less social support were worse off right after the heart event and up to one year later. Those with less support had significantly more symptoms of depression, poorer health, and lower quality of life, the researchers found. Similarly, a study conducted by Cockerham (2010) found that patients living with heart disease who received proper social support - in the form of emotional (e.g. nurturance), tangible (e.g. financial assistance), informational (e.g. advice), or companionship (e.g. sense of belonging), and intangible (e.g. personal advice) support appeared to have a better prognosis than those who did not. Many studies have been conducted around the social factors contributing to heart disease, but the social support studies among heart disease patients are scarce. The aim of this paper was to give a narrative account of what is already currently available, accessible and published, which may be written from a number of different paradigms or perspectives about social support among heart disease patients. For this reason, the researcher decided to conduct a critical review of literature.

\section{Materials and methods}

The review search for articles written in English was based on a selection of published literature, predominantly in the social support arena. Studies were included independent of publication date. Keywords were social support, heart disease, and patients. The review adopted a qualitative meta-synthesis approach. The researcher critically reviewed existing scholarly publications, including books and articles. No field work was conducted. This article is therefore purely theoretical and literature-based. Thus, the study has used both primary and secondary sources. The researcher has used thematic analysis to analyze the findings into themes.

\subsection{Inclusion criteria}

Only papers which discussed social support among heart disease patients were selected. Papers with a qualitative research focus published were included in the narrative review, whereas papers with a quantitative research focus were excluded.

\subsection{Literature source and data sources}

The literature search included published papers from several databases in English namely EBSCOhost, MEDLINE, Science Direct, Elsevier as well as Google Scholar, using keywords such as social support available, social support actions, social support factors, social support challenges. The searches resulted in 642 references from EBSCOhost, 446 references from MEDLINE, 721 from Science Direct, 123 from Elsevier, and 352 from Google Scholar. All results were downloaded and stored in the reference database program EndNote 7. From the total of 2,284 references, 1,769 references remained after deletion of duplicates.

\subsection{Study deletion}

Of the 1,769, 1,640 papers were excluded by title and abstract (Figure 1). Full texts of the remaining 129 papers were retrieved and screened for final inclusion. An additional 98 papers were excluded after evaluation of full text due to the date of publication, which was older than 
seven years. Finally, there were 31 potentially appropriate papers to be included in the review. For a reliability analysis of the selection process, two experts from another university independently reviewed the suitability of the 31 papers. A further 25 papers were excluded due to lack of relevant information; the information contained was relevant for discussion purposes only. In total there were 6 papers with sufficient information.

\subsection{Data extraction and analysis}

For data extraction, a paper-and-pen extraction sheet was used. Four columns were drawn namely social support available to heart disease patients; supportive actions beneficial to heart disease patients; social factors contributing to heart diseases; and social support challenges. Data from all included papers were independently coded by three data collection assistants into the four columns. After the initial coding, findings were compared and the differences were resolved by means of discussions. The final coding was based on mutual consent. Main results and study flaws were summarized in a descriptive and narrative manner.

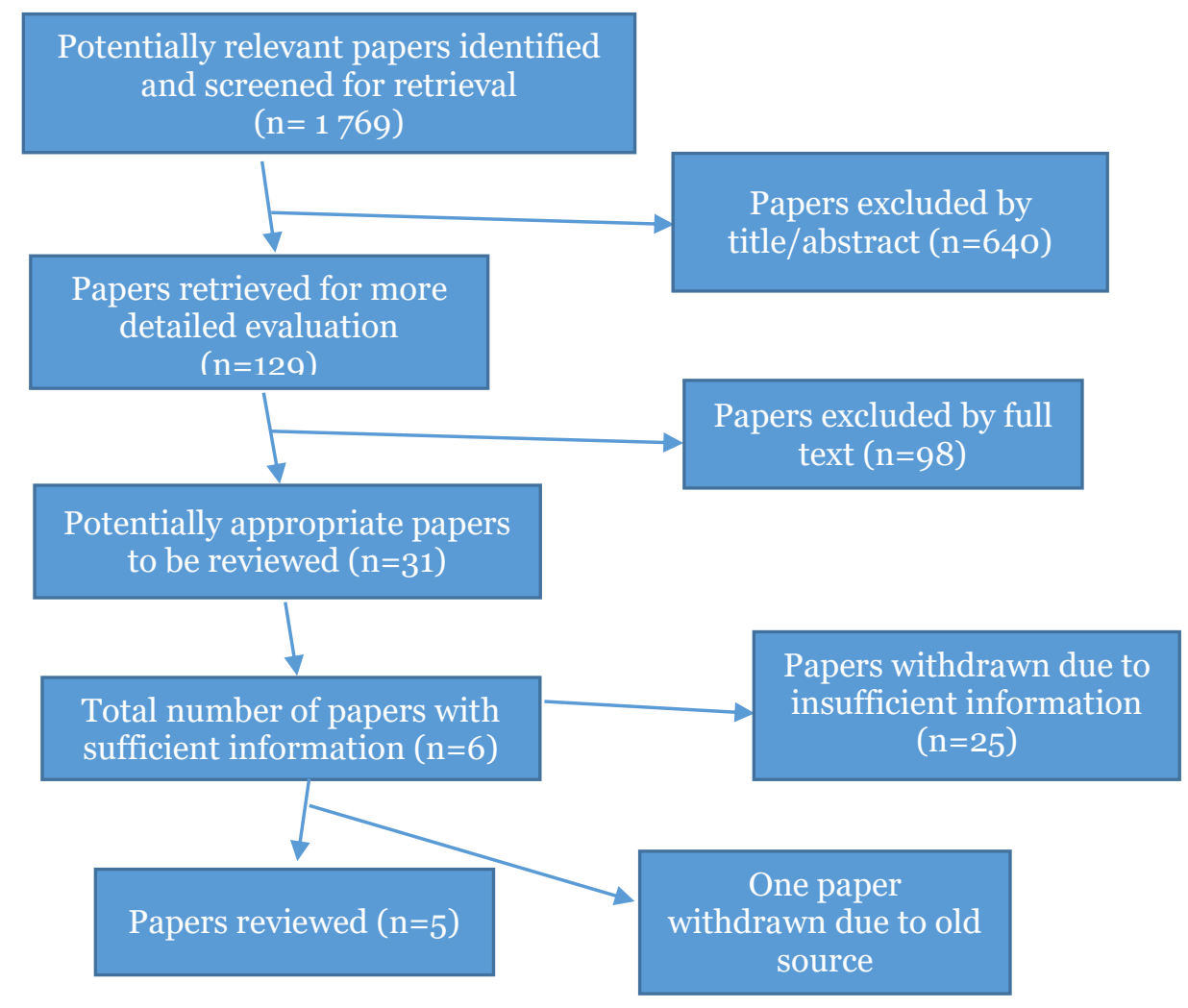

Figure 1: Review flow chart

Table 1: Examined studies regarding social support among heart disease patients.

\begin{tabular}{|c|c|}
\hline Study & Area of focus \\
\hline $\begin{array}{c}\text { Barth, J., Schneider, B. S. and Von Kanel, } \\
\text { R. (2010). }\end{array}$ & Support available to heart disease patients. \\
\hline Heart failure matters (2014). & $\begin{array}{c}\text { Support available to heart disease patients; social } \\
\text { factors contributing to heart diseases; supportive } \\
\text { actions beneficial to heart disease patients. }\end{array}$ \\
\hline
\end{tabular}




\begin{tabular}{|c|c|}
\hline $\begin{array}{c}\text { Compare, A., Zarbo, C., Manzoni, G. M. } \\
\text { et al. (2013). }\end{array}$ & $\begin{array}{c}\text { Support challenges; support available to heart disease } \\
\text { patients; supportive actions beneficial to heart disease } \\
\text { patients. }\end{array}$ \\
\hline Preidt, R. (2014). & $\begin{array}{c}\text { Social support challenges; social factors contributing to } \\
\text { heart diseases; supportive actions beneficial to heart } \\
\text { disease patients. }\end{array}$ \\
\hline Thomas, C. (2014). & $\begin{array}{c}\text { Social support challenges; supportive actions; } \\
\text { supportive actions beneficial to heart disease patients. }\end{array}$ \\
\hline Heartnews (2014). & $\begin{array}{c}\text { Support available; social support challenges; } \\
\text { supportive actions beneficial to heart disease patients. }\end{array}$ \\
\hline
\end{tabular}

\section{Results and discussions}

The findings from six studies were classified into four main themes namely, social support available to heart disease patients; supportive actions beneficial to heart disease patients; social factors contributing to heart diseases and social support challenges experienced by heart disease patients.

\subsection{Social support available to heart disease patients}

The critical review revealed that inadequate social support or a lack of social support such as the following is a risk factor for the development of heart diseases in previously healthy individuals; and that it also worsens the prognosis of patients with established diagnosis of heart disease (Barth et al., 2010):

- Functional support in the form of helping to get tasks done (instrumental support); providing information (informational support); help evaluating a situation (appraisal support); personal advice (tangible support) and feeling of being loved (emotional support) (Cockerham, 2010);

- Structural support in the form of number of contacts of network size, frequency of contacts, membership of community group and marital status (Cramer et al., 2015);

- Psychological and emotional recovery counselling sessions; physical recuperation exercises (physical therapy) three times a week and cognitive therapy once a week; and caregiver support in the form of doctors, nurses, psychologists and social workers (Holm et al., 2014).

Other forms of social support available to heart disease patients include information on the internet; church or religious affiliation support; resourceful husband support; resourceful wife support; esteem support and kinship support (Rubin, 2014). High social support is always shown to protect cardiac patients from negative prognostic consequences of depression (Pimple et al., 2014).

Researchers know that having social support from others following a diagnosis of heart disease helps not only with physical recuperation, but also with emotional and psychological recovery. According to Alzi et al. (2014), low functional support is strongly associated with higher mortality in patients with heart disease. In addition, Chrysohoou et al. (2014) emphasize that a network in the form of a heart failure support group; peer-to-peer support, group meetings and online network support offers a shared place for people to find emotional support from others who are going through similar journeys. Thus, sharing stories, experiences and practical advice can really make a positive impact on how challenges of heart diseases are dealt with. 


\subsection{Supportive actions most beneficial to heart disease patients}

The following supportive actions were identified by Suita (2015), Van de Vijver et al. (2013), WHO (2012), and WHO (2014), as the most beneficial to heart disease patients:

- Frequent visits by family members and friends;

- Strong familial ties;

- Donations of goods;

- Intimacy/love;

- Guidance and advice;

- Assistance in the form of getting kids to school, fetching kids from school, bathing kids, cleaning, doing laundry, cooking and washing dishes, and so forth;

- Positive appraisal of prognosis;

- Men prefer partner involvement;

- Young people prefer large social networks.

\subsection{Social factors contributing to heart diseases}

The review revealed that various psychosocial factors such as social isolation, neglect, loneliness and the absence of a confidant; depression, anxiety and worries; personality characteristics such as Type A, C and D; and chronic life stress and social stress predict the development, the course and negative prognosis of heart diseases (Barth et al, 2010). According to Lee et al. (2012), heart disease patients with low social support tend to have heart disease risk factors such as high blood pressure and depression. Thus, depression might further predispose them to alcohol abuse and smoking, risky lifestyles and behavior such as physical inactivity and poor diets leading to obesity (Nikpou, Gladman \& Urowitz, 2013). Other social factors contributing to heart disease outlined in various sources include socio-economic conditions and poverty (Oerkild et al., 2011); network dissatisfaction and perceptions of less available support (Owolabi et al., 2014); low levels of education/lack of information among isolated survivors (Paguntalan \& Gregoski, 2015); peer pressure; and gender and sex differences (Peer et al., 2012).

\subsection{Social support challenges experienced by heart disease patients}

Biccard and Nepaul (2010) assert that patients with low social support tend to be single/ widowed/divorced individuals who live alone; who smoke and abuse alcohol. This is more painful because - as Thomas (2014) points out - young women may be at an increased risk of low social support, both at the time of their heart disease and during the course of recovery, which may increase their risk of adverse outcomes. In addition, women receive less information about their disease from providers (Kohl et al., 2012); and women, irrespective of age, tend to receive less assistance with household duties from informal caregivers, yet household activities are more important to them than to men (Lang et al., 2012). Other social support challenges identified by Noakes et al. (2014) include difficulty finding a personal connection with someone with similar experience; non-availability of psychologists and social workers; no advice on available resources in the area; few social networks, particularly among males; and that no one asks on discharge if the patient will need help at home taking care of self or children.

\section{Conclusion}

The findings of this critical literature review showed that heart disease patients have a variety of social support choices at their disposal - from friends, peers, their spouse, church members, family members and care group in the form of functional and structural support. It also 
became evident that heart disease patients benefit mostly from actions which demonstrate love such as frequent visits, strong ties, donations of goods, assistance with household chores, guidance and advice and positive prognosis appraisal. However, social factors contributing to heart disease such as personality characteristics, lack of information, or chronic stress determine prognosis especially when triggered by social challenges such as being single, no one caring, and so forth.

\section{Recommendations}

Social support must be taken seriously by nurses, psychologists, and physicians to structure effective interventions with the aim of improving health outcomes and reducing the risk of mortality and morbidity in heart disease patients. There may be some utility in being able to identify patient support networks when patients are first admitted for heart disease. The information identified from this critical review of literature may be used to develop a clinical assessment tool to obtain baseline social support information from every heart disease patient. Such information may inform individual social support interventions. In addition, the information may be used to develop a social support model for heart disease patients.

\subsection{Clinical considerations}

The findings of this review are consistent with previous studies which suggest new ways of helping heart disease patients. Immediately after heart disease diagnosis, as well as during the evaluation and waiting list for heart surgeries and interventions, relatives and friends may help cardiac patients to cope with physical disability, limitation of personal autonomy and with a sense of uncertainty about the future. It was proposed in the literature that psychosocial interventions aimed at improving mental health, quality of life, and compliance after a cardiac event be extended to family caregivers (Dalal et al., 2011). Recently, intervention programs such as peer mentor support have been developed to improve or enhance social support in patients with heart diseases (Maredza, Hofman \& Tollman, 2011). Identifying and reinforcing current social support networks and the quality of these networks may help to improve adherence behavior, in particular in patients who show symptoms of depression. Future reviews should include more studies - to have a complete overview of the topics and to provide the basis to investigate how social support can be

enhanced by nurses, families, and psychologists in patients at risk of recurrent cardiac events and high levels of depression.

\section{Acknowledgements}

This research did not receive any specific grant from funding agencies in the public commercial, or not-for-profit sectors.

The author declares no competing interests. 


\section{References}

Alzi, B. B., Ahmad, A. Z., Mala, A. M., Rashidah, A., Mohamad, H. A., Balkish, M. N., Siew, M. C., Chan, Y. Y., Hazizi, A. S., \& Noor, A. A. (2014). Factors associated with physical inactivity among schoolgoing adolescents: Data from the Malaysian School-Based Nutrition survey 2012. Asia-Pacific Journal of Public Health, 26(5), 27-35.

Barth, J., Schneider, B. S., \& Von Kanel, R. (2010). Lack of social support in the aetiology and prognosis of coronary heart disease: A systematic review and meta-analysis. Psychosomatic Medicine, 72, 229-238.

Biccard, B. M., \& Nepaul, S. (2010). Risk factors associated with intermediate and long-term mortality following vascular surgery in South African patients. Cardiovascular Journal of Africa, 21(5), 263-267.

Chrysohoou, C., Esposito, K., Giugliano, D., \& Panagiotakos, D. (2014). Peripheral arterial disease and cardiovascular risk: The role of the Mediterranean diet. Angiology, 1-3.

Cockerham, W.C. (2010). Medical sociology. Upper Saddle River, NJ: Pearson.

Compare, A., Zarbo, C., Manzoni, GM. et al. (2013). Social support, depression, and heart disease: A ten year literature review. Frontiers in Psychology, 6(1), 384.

Cramer, H., Lauche, R., Haller, H., Dobos, G., \& Michalsen, A. (2015). A systematic review of yoga for heart disease. European Journal of Preventive Cardiology, 22(3), 284-295.

Dalal S., Beunza J. J., Volmink, J., Adebamowo, C., Bajunirwe, F., \& Njelekela, M. (2011). Noncommunicable diseases in sub-Saharan Africa: What we know now. International Journal of Epidemiology, April: 228.

Heart failure matters (2014). Support. www.heartfaiulrematters.org/en-GB/living.

Heartnews (2014). Low social support linked to poor health in young heart attack survivors. American Heart Association Rapid Access Journal Report. September 30.

Holm, A. L., Bronnum-Hansen, H., Robinson, K. M., \& Diderichsen, F. (2014). Assessment of health impacts of decreased smoking prevalence in Copenhagen: Application of the DYNAMO-HIA model. Scandinavian Journal of health Public Health, 2014(42), 409-416.

Kohl, H., Craig, C. L., Lambert, E. V., Inoue, S., Alkandari, J. R., Leetongin, G., \& Kahlmeier, S. (2012). The pandemic of physical inactivity: Global action for public health. The Lancet, 380(12), 294-305.

Lang, T., Lepage, B., Schieber, A., Lamy, S., \& Kelly-Irving, M. (2012). Social determinants of cardiovascular diseases. Public Health Reviews, 33(2), 601-622.

Lee, M., Shiroma, E. J., Lobelo, F., Puska, P., Blair, S. N., \& Katzmarzyk, P. (2012). The effect of physical inactivity on major non-communicable diseases worldwide: an analysis of burden of disease and life expectancy. The Lancet, $380(12), 192-193$.

Maredza, M., Hofman, K. J., \& Tollman, S. M. (2011). A hidden menace: cardiovascular disease in South Africa and costs of an inadequate policy response. South African Heart Association, 1(8), 4857.

Nikpour, M., Gladman, D. D. \& Urowitz, M. B. (2013). Premature coronary heart disease in systemic lupus erythematosus: what risk factors do we understand? Sage Journal, 2013(22), 1243-1250.

Noakes, T., Creed, S.-A., Proudfoot, J., \& Grier, D. (2014). The real meal revolution: Changing the world, one meal at a time. Quivertree Publications (Original South Africa edition).

Oerkild, B., Frederiksen, M., Hansen, J. E. \& Prescott, E. (2011). Self-reported physical inactivity predicts survival after hospitalization for heart disease. European Journal of Cardiovascular Prevention \& Rehabilitation, 18(3), 475-480. 
Owolabi, M. O., Mensah, G. A., Kimmel, P. L., Adu, D., Ramsay, M., Waddy, S. P., Ovbiagele, B., RabadanDiehl, C., Rasooly, R., Akarolo-Anthony, S. N., \& Rotimi, C. (2014). Understanding the rise in cardiovascular diseases in Africa: harmonizing H3Africa genomic epidemiological teams and tools. Cardiovascular Journal of Africa, 3(25), 134-136.

Paguntalan, J., \& Gregoski, M. (2015). An integrative review of self-report instruments for measuring physical activity among African American women: A coronary heart disease perspective. Journal of Black Studies, 46(2), 218-236.

Peer, N., Steyn, K., Lombard, C., Lambert, E. V., Vythilingum, B., \& Levitt, N. S. (2012). Rising diabetes prevalence among urban-dwelling black South Africans. Open access; free online.

Pimple, P., Shah, A., Rooks, C., Bremner, J. D., Nye, J., Ibeanu, I., Murrah, N., Shallenberger, L., Kelley, M., Raggi, P., \& Vaccarino, V. (2014). Association between anger and mental stress-induced myocardial ischemia: Imaging and diagnostic testing. American Heart Journal, 169, 115-121.

Preidt, R. (2014). Healthday reporter. www.webmd,com/heart/news/20140930/soial-support.

Rubin, E. (2014). To drink or not to drink: that is the question. Alcohol Clinical Experimental Research, 12(38), 2889-2892.

Sunita, K. (2015). Determination of macro and micro nutrients and nutritional profile of vegetables. Asian Journal of Biosciences, $10(2), 178-182$.

Thomas, C. (2014). Little social support: A big gap for younger heart patients. Heart sister. http://myheartsisters.org/2014/low-socialsupport.

Van de Vijver, S., Akinyi, H., Oti, S., Olajide, A., Agyemang, C., Aboderin, I., \& Kyobutungi, C. (2013). Status report on hypertension in Africa - Consultative Review for the 6th Session of the African Union Conference of Ministers of Health on NCD's. Pan African Medical Journal, 2013, 16-38.

WHO (2012). World Health Organisation, obesity and overweight. Fact sheet number 311. Geneva: WHO. WHO (2014). Global status report on non-communicable disease. Geneva: WHO. 